\title{
EFFECT OF INTRATHECAL CLONIDINE ON DURATION OF SPINAL
}

\section{ANALGESIA}

Sourabh Shrivastava ${ }^{1}$, Divya Sinha², Swati Shrivastava ${ }^{3}$

\section{HOW TO CITE THIS ARTICLE:}

Sourabh Shrivastava, Divya Sinha, Swati Shrivastava. "Effect of Intrathecal Clonidine on Duration of Spinal Analgesia". Journal of Evolution of Medical and Dental Sciences 2015; Vol. 4, Issue 45, June 04;

Page: 7777-7784, DOI: $10.14260 /$ jemds/2015/1131

\begin{abstract}
BACKGROUND: Clonidine is an $\alpha_{2}$ adrenoreceptor agonist that has been shown to effectively prolong the duration of analgesia when administered intrathecally or in the epidural space along with local anaesthetic. AIMS AND OBJECTIVE: This study was designed to evaluate the effect of two different doses of intrathecal clonidine $(37.5 \mu \mathrm{g}$ and $75 \mu \mathrm{g})$ on the duration of analgesia and side effects produced by hyperbaric bupivacaine 0.5\%. MATERIALS AND METHODS: A prospective hospital based, randomized and double blind study. Selected 75 patients who was scheduled for elective below umbilical surgeries were randomly allocated to one of three groups. Group I ( $n=25$, control group) received 3ml hyperbaric bupivacaine, Group II ( $\mathrm{n}=25) 3 \mathrm{ml}$ hyperbaric bupivacaine + $37.5 \mu \mathrm{g}$ clonidine and Group III $(\mathrm{n}=25) 3 \mathrm{ml}$ hyperbaric bupivacaine $+75 \mu \mathrm{g}$ clonidine intrathecally. Total volume $(4 \mathrm{ml})$ remained constant by adding sterile water. Data were analyzed by using SPSS software ver.18. RESULTS: The (mean \pm SD) duration of analgesia was found to be $171.3 \pm 6.37$ mins in Group I, 217.7 \pm 7.01 mins in Group II and 257.1 \pm 6.50 mins in Group III $(\mathrm{p}<0.05)$. It shows that $37.5 \mu \mathrm{g}$ \& $75 \mu \mathrm{g}$ intrathecal clonidine increases the duration of analgesia of $15 \mathrm{mg}$ hyperbaric bupivacaine by about 46 mins \& 86 mins respectively. The addition of intrathecal clonidine upto $75 \mu \mathrm{g}$ does not cause any significant major side effect except mild sedation, without an increase in incidence of hypotension, bradycardia and respiratory depression. CONCLUSION: Intrathecal clonidine (37.5 $\mu$ g \& $75 \mu \mathrm{g}$ ) as an adjuvant to hyperbaric bupivacaine $0.5 \%$ prolong the duration of analgesia in a dose dependent manner without increase in incidence of significant side effects.
\end{abstract}

KEYWORDS: hyperbaric bupivacaine, intrathecal clonidine, spinal anaesthesia.

INTRODUCTION: Spinal anaesthesia is a well-established technique. It is easy to perform, to provide fast onset and effective sensory and motor block. Now a days bupivacaine is a commonly used local anaesthetic drug in spinal anaesthesia. However duration of spinal analgesia by bupivacaine is limited upto 75-150 min. Therefore various additives like clonidine, opioids, neostigmine, ketamine and epinephrine separate or in combination were used along with bupivacaine for prolongation of the effect, to improve the quality of analgesia and to minimize the requirement for postoperative analgesics.

Clonidine is an $\alpha_{2}$ adrenoreceptor agonist that has been shown to effectively prolong the duration of analgesia when administered intrathecally or in the epidural space.(1,2,3)

The $\alpha_{2}$ adrenergic agonist clonidine has a variety of different actions including the ability to potentiate the effects of local anaesthetics. Such prolongation of the effects of local anesthetics has been reported with oral. (4) IV (5) and intrathecal clonidine.(6,7)

However, unlike spinal opioids, clonidine does not produce pruritus, urinary retention, respiratory depression, vomiting with no or minimum CNS depression. However, intrathecal clonidine at high doses is associated with bradycardia, hypotension and sedation. 
Whereas a recent report established $1-2 \mu \mathrm{g} / \mathrm{kg}$ intrathecal clonidine as an adequate dose for prolonging plain bupivacaine spinal anaesthesia in newborns,(3) the optimal dose in adults in terms of effects versus side effects of intrathecal clonidine by itself is controversial.(8,9,10) A marked decrease in arterial blood pressure was observed with $75 \mu \mathrm{g}$ of intrathecal clonidine (in combination with intrathecal morphine), (8) whereas relative hemodynamic stability was maintained with doses $\geq 150$ $\mu \mathrm{g}$, as demonstrated by using clonidine as a sole adjuvant.(10) However, in the dose range of 150$450 \mu \mathrm{g}$, clonidine causes marked sedation.(10) Because of this clinically relevant side effect, there is a tendency toward the use of smaller doses $(<150 \mu \mathrm{g})$. Such doses of clonidine producing only minimal side effects would be a true easy, safe, cost effective alternative to other technical or pharmacological procedures aimed at prolonging spinal analgesia, such as combined spinal epidural anaesthesia (Technically more difficult and risky) or intrathecal opioids(more adverse effects).

The present study evaluate effects of clonidine (different doses) $37.5 \mu \mathrm{g} \& 75 \mu \mathrm{g}$ on duration of analgesia and side effects produced by hyperbaric bupivacaine $0.5 \%$.

MATERIALS AND METHODS: A prospective hospital based, randomized and double blind study was carried out in the Department of Anaesthesiology, G R Medical College, Gwalior (M.P.) after the approval of college ethical committee. The study was done on 75 patients of ASA grade I \& II of either sex with age group 20-60 years scheduled for below umbilical surgeries.

Exclusion Criteria for patients: Known history of sensitivity to bupivacaine. Body weight $>100$ $\mathrm{kg}$ and $<45 \mathrm{~kg}$ and height $<145 \mathrm{~cm}$. Patients on any drug treatment. Patient's having systemic disease, coagulopathy and bleeding disorders. History of spinal cord surgery, vertebral deformities, infection at site of block. Those patients who did not develop Grade III motor blockade were excluded from study.

Consent-Details of procedure were explained to all the patients preoperatively and a informed consent was obtained.

\section{Patients Grouping:}

Selected 75 patients were divided randomly in three groups depending upon the different doses of clonidine given.

1. Control Group $\mathrm{I}(\mathrm{n}=25)$ patients, received intrathecally $3 \mathrm{ml}$ of hyperbaric Bupivacaine $0.5 \%+$ $1 \mathrm{ml}$ of Sterile Water.

2. Group II $(\mathrm{n}=25)$ patients, received intrathecally $3 \mathrm{ml}$ of hyperbaric Bupivacaine $0.5 \%+0.25 \mathrm{ml}$ of Clonidine $(37.5 \mu \mathrm{g})+0.75 \mathrm{ml}$ of Sterile Water.

3. Group III ( $\mathrm{n}=25)$ patients, received intrathecally $3 \mathrm{ml}$ of hyperbaric Bupivacaine $0.5 \%+0.5 \mathrm{ml}$ of Clonidine $(75 \mu \mathrm{g})$ ) $+0.5 \mathrm{ml}$ of Sterile Water.

TECHNIQUE: All the patients were to be kept nil orally for at least 6 hours before procedure. Uniform pre medication of Injection Glycopyrrolate $0.2 \mathrm{mg}$ I.M. was given 30 minutes before induction of anaesthesia. Intradermal sensitivity test of Bupivacaine was performed. Preloading of 1 liter RL was started with $18 \mathrm{G}$ Cannula, $1 / 2$ hour before start of anaesthesia.

After careful aseptic cleaning and draping, a midline subarachnoid block was performed at L2/3 or L3/4 intervertebral space with the patient in the lateral decubitus position using a 25-gauge Quincke spinal needle. After free flow of CSF drug was injected at a rate of about $1 \mathrm{~mL}$ in 4-5 seconds. Thereafter, the patients were placed in the supine position for surgery. During surgery crystalloids, 


\section{ORIGINAL ARTICLE}

colloids and blood were administered according to requirement to maintain hemodynamic stability. The drug combinations were prepared by first author, however various observations were made by a second anaesthesiologist who was involved after the procedure had been performed.

INTERVENTIONS AND OBSERVATIONS: After the drug was injected following parameters were recorded.

MONITORING: Baseline observations preoperatively were started before intrathecal drug injection. Pulse rate, electrocardiogram, systolic and diastolic BP, respiratory rate and peripheral arterial haemoglobin oxygen saturation $\left(\mathrm{SpO}_{2}\right)$ were monitored intraoperatively. Data monitoring performed continuously but for study purpose data were recorded at $0,10,20,40,60$ minutes after intrathecal injection and thereafter every hour up to 8 hours.

Criteria for (a) Bradycardia: a pulse rate of $60 / \mathrm{min}$ or less, was treated by injection atropine intravenously. (b) Hypotension: a fall in systolic BP 30\% or greater from the base line value was treated by injection mephentermine intravenously, intravenous fluids (crystalloid, colloid and blood) as per requirement and oxygen by face mask. (c) Respiratory depression: a respiratory rate of less than 10 breaths per min or $\mathrm{SpO}_{2}<90 \%$ was treated by oxygen supplementation through face mask.

\section{ANALGESIA PARAMETERS:}

a) Onset time of sensory blockade: Time from intrathecal drug injection to loss of sensation in any of dermatome upto T10 level by pin prick.

b) Duration of analgesia (pain relief): Time taken from onset of sensory block to the first request for supplemental analgesia.

C) Intensity of pain and VAS (Visual analogue scale) at the time of first analgesia request: Assessment of pain was done by VAS. The VAS was first described by Pilowsky I and Bond MR. It is a $10 \mathrm{~cm}$ scale with 100 divisions drawn on white paper representing pain.VAS SCORE RATING: (0: NO PAIN, 1-25: MILD PAIN, 26-50: MODERATE PAIN, 51-76: SEVERE PAIN, 76100: VERY SEVERE PAIN)

When patient complained of pain postoperatively, VAS score at the time of first analgesia request recorded. Then intramuscular diclofenac sodium $75 \mathrm{mg}$ was prescribed and the study of that patient was taken as complete. All patients were followed for 24 hours.

SIDE EFFECTS AND COMPLICATIONS: Patients were closely observed in the intraoperative and postoperative period for complications like nausea, vomiting, dyspnoea, respiratory depression, chest pain, sedation, shivering, dysrhythmia, bradycardia, hypotension and any other.

\begin{tabular}{|l|c|}
\hline 0 & Alert \\
\hline 1 & Amnesia \\
\hline 2 & Asleep but arousable \\
\hline 3 & Unarousable with loss of verbal contact \\
\hline \multicolumn{2}{|c|}{ Sedation score: Sedation is assessed by sedation score } \\
\hline
\end{tabular}


STATISTICAL ANALYSIS: The sample size was calculated using the appropriate formula Z2 PQ/d2 where $P \& Q$ were taken as 0.5 to get the maximum sample size with $10 \%$ permissible error and $5 \%$ non-response rate with 85 percent confidence interval. The data was entered in MS Excel and analyzed using SPSS ver. 18. Standard statistical techniques were applied according to suitability of data. Significance of differences in the outcome variable between groups was tested by $\mathrm{Z}$ test for two proportion, ANOVA was used for comparing the significance difference between three groups. ' $p$ ' value less than 0.05 was considered statistically significant.

RESULTS: There was no statistically significant difference about demographic variables like age, weight, height, sex and duration of surgery in all the 3 groups as ( $p>0.05)$. (Table no. 1)

The (mean \pm SD), onset time of sensory blockade was found to be $71.4 \pm 6.21$ seconds, $71 \pm 5.40$ seconds and 70.8 \pm 5.33 seconds in Group I, Group II and Group III respectively. On intergroup comparison, this difference was found to be statistically insignificant ( $p>0.05)$. (Table no. 2).

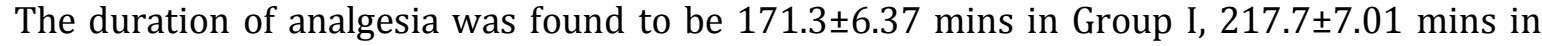
Group II and 257.1 \pm 6.50 mins in Group III. On intergroup comparison, this difference was found to be statistically significant $(\mathrm{p}<0.05)$. (Table no. 2). The duration of analgesia was prolonged by about 46 mins in Group II \& about 86 mins in Group III.

The VAS at time of first analgesia request was $38.38 \pm 2.83$ in Group I, 38.8 \pm 4.08 in Group II and 38.64 \pm 3.25 in Group III. On intergroup comparison, this difference was found to be statistically insignificant in all the three groups ( $p>0.05)$. (Table no. 2)

Four patients (16\%) in Group III \& Group II and two patients (8\%) in Group I developed bradycardia in our study. On intergroup comparison, this difference was found to be statistically insignificant ( $\mathrm{p}>0.05)$. (Table no. 3)

There was no incidence of hypotension in any group. (Table no. 3).

2 patients (8\%) in Group I, III and 1 patient (4\%) in Group II had nausea and vomiting. On intergroup comparison, this difference was found to be statistically insignificant as ( $>>0.05)$. (Table no. 3)

None of the patients in all the three groups had respiratory depression, dyspnoea \& chest pain. (Table no. 3)

Only the two patients (8\%) in Group I develop shivering and none in Group II and III. (Table no. 3)

Only the two patients (8\%) in Group III found amnesic (sedation score 1) and none in Group II and Group I. (Table no. 3)

DISCUSSION: Clonidine is a selective partial agonist for $\alpha_{2}$ adrenoceptors. $\alpha_{2}$ adrenoceptors are located on primary afferent terminals (both at peripheral and spinal endings), on neurons in the superficial laminae of the spinal cord, and within several brainstem nuclei implicated in analgesia, supporting the possibility of analgesic action of clonidine at peripheral, spinal, and brainstem sites.

Our study indicates that intrathecal clonidine $(37.5 \mu \mathrm{g} \& 75 \mu \mathrm{g})$ does not affect the onset time of sensory blockade induced by hyperbaric bupivacaine. Elia N. et al,(11) conducted a systemic review of 22 randomized trials. They found that clonidine 15 to $150 \mu \mathrm{g}$ when used as an adjuvant to intrathecal local anaesthetic prolonged the time to 2 segment regression (sensory blockade) without affecting the onset of spinal anaesthesia. Braz J.R. et al,(12) also found that $75 \mu \mathrm{g}$ intrathecal clonidine does not affect the onset of sensory block produced by $17.5 \mathrm{mg} 0.5 \%$ hyperbaric bupivacaine. 
In our study, the duration of analgesia was prolonged by about 46 mins in Group II \& about 86 mins in Group III. This shows that intrathecal cloonidine $(37.5 \mu \mathrm{g} \& 75 \mu \mathrm{g})$ increase the duration of analgesia in a dose dependent manner. This result is supported by Van Tuijl I. et al. ${ }^{13}$ Braz J. R. et al, 12 found that intrathecal clonidine ( 45 and $75 \mu \mathrm{g}$ ) an adjuvant to hyperbaric bupivacaine prolong the duration of postoperative analgesia. Elia N. et al,11 and Sethi B. S. et al,(14) also found similar results.

The analgesic effect following intrathecal administration of clonidine is mediated spinally through activation of post synaptic $\alpha 2$ receptors in substantia galatinosa of spinal cord. The rationale behind intrathecal administration of clonidine is to achieve a high drug concentration in the vicinity of $\alpha 2$ adrenoceptors in spinal cord and it works by blocking the conduction of $\mathrm{C} \& \mathrm{~A} \delta$ fibers, increases potassium conductance in isolated neurons in vitro and intensifies conduction block of local anaesthetics.(14)

We also found that intrathecal clonidine in doses upto $75 \mu \mathrm{g}$ does not increase the incidence of bradycardia and hypotension. Benhamou D. et al 15 found that intrathecal clonidine (75 $\mu \mathrm{g}$ ) as an adjuvant to hyperbaric bupivacaine produce no significant changes in blood pressure and heart. Seah Y.S. et al, 16 also reported that side effects such as hypotension and bradycardia are more common in patients who received $150 \mu \mathrm{g}$ intrathecal clonidine as an adjuvant to hyperbaric bupivacaine as compared to patient's in control group.

Clonidine reduces heart rate by stimulating presynaptic $\alpha 2$ receptors present in medulla and hypothalamus which decreases sympathetic out flow and partly by a vagomimetic effect. The clonidine produces sympatholysis and reduce arterial blood pressure through effects at multiple specific brainstem nuclei \& on sympathetic preganglionic neurons in the spinal cord, effects that are counteracted by direct vasoconstriction resulting from $\alpha 2$ adrenergic agonist on the peripheral vasculature.(17)

In our study patients did not differ in their VAS scores at the time of first analgesia request. Our study shows that intrathecal clonidine (upto75 $\mu$ g) does not increase the incidence of nausea, vomiting, respiratory depression, dyspnoea, chest pain, shivering and deep sedation. Sethi B. S. et al,(14) concluded that addition of clonidine $1 \mu \mathrm{g} / \mathrm{kg}$ to $12.5 \mathrm{mg} 0.5 \%$ bupivacaine does not produce respiratory depression. Heo G.J. et al,18 found no significant differences in sedation and other side effects between clonidine treated group and control group. The overall principle finding of this study that addition of clonidine upto $75 \mu \mathrm{g}$, intrathecally did not cause any significant major side effect except mild sedation without an increase in incidence of hypotension, bradycardia and respiratory depression.

CONCLUSION: Intrathecal clonidine $(37.5 \mu \mathrm{g} \& 75 \mu \mathrm{g})$ as an adjuvant to hyperbaric bupivacaine $0.5 \%$ prolong the duration of analgesia in a dose dependent manner without increase in incidence of significant side effects.

\section{REFERENCES:}

1. Ansermino M, Basu R, Vandebeek C, Montgomery C. Nonopioid additives to local anaesthetics for caudal blockade in children: a systematic review. Paediatr Anaesth 2003; 13: 561-73.

2. Constant I, Gall O, Gouyet L, et al. Addition of clonidine or fentanyl to local anaesthetics prolongs the duration of surgical analgesia after single shot caudal block in children. Br J Anaesth 1998; 80: 294-8. 


\section{ORIGINAL ARTICLE}

3. Rochette A, Raux 0 , Troncin $\mathrm{R}$, et al. Clonidine prolongs spinal anesthesia in newborns: a prospective dose-ranging study. Anesth Analg 2004; 98: 56-9.

4. Liu S, Chiu AA, Neal JM, et al. Oral clonidine prolongs lidocaine spinal anesthesia in human volunteers. Anesthesiology 1995; 82: 1353-9.

5. Rhee K, Kang K, Kim J, Jeon Y. Intravenous clonidine prolongs bupivacaine spinal anesthesia. Acta Anaesthesiol Scand 2003; 47: 1001-5.

6. Dobrydnjov I, Axelsson K, Samarutel J, Holmstrom B. Postoperative pain relief following intrathecal bupivacaine combined with intrathecal or oral clonidine. Acta Anaesthesiol Scand 2002; 46: 806-14.

7. Bonnet F, Buisson VB, Francois Y, et al. Effects of oral and subarachnoid clonidine on spinal anesthesia with bupivacaine. Reg Anesth 1990; 15: 211-4.

8. Grace D, Bunting H, Milligan KR, Fee JP. Postoperative analgesia after co-administration of clonidine and morphine by the intrathecal route in patients undergoing hip replacement. Anesth Analg 1995; 80: 86-91.

9. Chiari A, Lorber C, Eisenach JC, et al. Analgesic and hemodynamic effects of intrathecal clonidine as the sole analgesic agent during first stage of labor: a dose-response study. Anesthesiology 1999; 91: 388-96.

10. Filos KS, Goudas LC, Patroni O, Polyzou V. Hemodynamic and analgesic profile after intrathecal clonidine in humans: a dose-response study. Anesthesiology 1994; 81: 591-601.

11. Elia N, Culebras X, Mazza C, Schiffer E, Tramèr MR. Clonidine as an adjuvant to intrathecal local anesthetics for surgery: systematic review of randomized trials..Reg Anesth Pain Med. 2008 Mar-Apr; 33(2): 159-67. Review.

12. Braz JR, Koguti ES, Braz LG, Croitor LB, Navarro LH. Effects of clonidine associated to hyperbaric bupivacaine during high-level spinal anesthesia. Rev Bras Anestesiol 2003 Sep; 53(5): 561-7.

13. Van Tuijl I, van Klei WA, van der Werff DB, Kalkman CJ. The effect of addition of intrathecal clonidine to hyperbaric bupivacaine on postoperative pain and morphine requirements after Caesarean section: a randomized controlled trial. Br J Anaesth. 2006 Sep; 97(3): 365-70. Epub 2006 Jul 21.

14. B S Sethi, Mary Samuel, Deepak Sreevastava. Efficacy of analgesic effects of low dose intrathecal clonidine as adjuvant to Bupivacaine. IJA, 2007, 51(5); 415-419.

15. Benhamou D, Thorin D, Brichant JF, Dailland P, Milon D, Schneider M. Intrathecal clonidine and fentanyl with hyperbaric bupivacaine improves analgesia during cesarean section. Anesth Analg. 1998 Sep; 87(3): 609-13.

16. Seah YS, Chen C, Chung KD, Wong CH, Tan PP.Prolongation of hyperbaric bupivacaine spinal anesthesia with clonidine] [Clinical Trial, English Abstract, Journal Article, Randomized Controlled Trial]Ma Zui Xue Za Zhi 1991 Mar; 29(1): 533-7.

17. Strebel S, Gurzeler JA, Schneider MC, Aeschbach A, Kindler C. Small-dose intrathecal clonidine and isobaric bupivacaine for orthopedic surgery: a dose-response study. Anesth Analg. 2004 Oct; 99(4): 1231-8.

18. Heo GJ, Kim YH, Oh JH, Joo JC. Effect of Intrathecal Clonidine in Hyperbaric Bupivacaine Spinal Anesthesia. KoreanJ Anaesthesiology 1997 Aug. 33(2): 304-308. 


\section{ORIGINAL ARTICLE}

\begin{tabular}{|c|c|c|c|c|c|c|}
\hline \multirow{2}{*}{$\begin{array}{c}\text { Sl. } \\
\text { No. }\end{array}$} & \multirow{2}{*}{ Variable (N=25) } & \multicolumn{3}{|c|}{ Group (Mean \pm SD) } & \multicolumn{2}{c|}{ ANOVA } \\
\cline { 2 - 7 } & & I & II & III & F & P-value \\
\hline 1 & Age (Yr) & $41 \pm 10.72$ & $39.2 \pm 11.99$ & $41 \pm 11.51$ & 0.21 & 0.80 \\
\hline 2 & Height (Cm) & $162 \pm 5.50$ & $161 \pm 4.96$ & $162 \pm 4.41$ & 0.33 & 0.71 \\
\hline 3 & Weight (Kg) & $62 \pm 5.44$ & $63 \pm 6.73$ & $63 \pm 5.71$ & 0.23 & 0.79 \\
\hline 4 & Duration of surgery (Min) & $123 \pm 21.75$ & $121 \pm 26.46$ & $121 \pm 25.47$ & 0.54 & 0.94 \\
\hline 5 & Sex (M:F) Table 1: Demographic Data & $14: 11$ & $13: 12$ & $14: 11$ & & \\
\hline \multicolumn{7}{|c}{} \\
\hline
\end{tabular}

\begin{tabular}{|c|c|c|c|c|c|c|}
\hline \multirow{2}{*}{$\begin{array}{l}\text { Sl. } \\
\text { No. }\end{array}$} & \multirow{2}{*}{ Parameters } & \multicolumn{3}{|c|}{ Group (Mean \pm SD) } & \multicolumn{2}{|c|}{ ANOVA } \\
\hline & & I & II & III & $\mathrm{F}$ & P-value \\
\hline 1 & $\begin{array}{c}\text { Onset time of sensory } \\
\text { blockade (seconds) }\end{array}$ & $71.4 \pm 6.21$ & $71 \pm 5.40$ & $70.8 \pm 5.33$ & 0.07 & 0.92 \\
\hline 2 & $\begin{array}{l}\text { Duration of analgesia } \\
\text { (min) }\end{array}$ & $171.3 \pm 6.37$ & $217.7 \pm 7.01$ & $257.1 \pm 6.50$ & 1048.2 & 0.00 \\
\hline 3 & $\begin{array}{l}\text { VAS at time of first } \\
\text { analgesia request }\end{array}$ & $38.38 \pm 2.83$ & $38.8 \pm 4.08$ & $38.64 \pm 3.25$ & 0.09 & 0.90 \\
\hline
\end{tabular}

\begin{tabular}{|c|c|c|c|c|c|}
\hline \multirow{2}{*}{$\begin{array}{c}\text { Sl. } \\
\text { No. }\end{array}$} & \multirow{2}{*}{ Complications } & \multicolumn{3}{|c|}{ Group } & \multirow{2}{*}{$\begin{array}{c}\text { P-value } \\
\text { (Z-test) }\end{array}$} \\
\cline { 3 - 5 } & & I (\%) & II (\%) & III (\%) & 0.80 \\
\hline 1 & Nausea and vomiting & 8 & 4 & 8 & - \\
\hline 2 & Respiratory depression & - & - & - & - \\
\hline 3 & Hypotension & - & - & - & 0.63 \\
\hline 4 & Bradycardia & 8 & 16 & 16 & - \\
\hline 5 & Shivering & 8 & - & - & - \\
\hline 6 & Dyspnoea & - & - & - & - \\
\hline 7 & Chest pain & - & - & - & - \\
\hline 8 & Sedation & - & - & 8 & - \\
\hline
\end{tabular}

Table 3: Showing incidence of side effects and complications in all the three groups 


\section{ORIGINAL ARTICLE}

\section{AUTHORS:}

1. Sourabh Shrivastava

2. Divya Sinha

3. Swati Shrivastava

\section{PARTICULARS OF CONTRIBUTORS:}

1. PGMO, Department of Anesthesia, G. R. Medical College, Gwalior, Madhya Pradesh.

2. PGMO, Department of Obstetric I.C.U, G. R. Medical College.

FINANCIAL OR OTHER

COMPETING INTERESTS: None
3. Ph.D. Scholar. Inspire Fellow, Department of Biochemistry, G.R. Medical College.

\section{NAME ADDRESS EMAIL ID OF THE} CORRESPONDING AUTHOR:

Dr. Sourabh Shrivastava, \# 91, Tansen Nagar,

Gwalior-474002,

Madhya Pradesh.

E-mail: sourabh_jitu@ymail.com

Date of Submission: 15/05/2015.

Date of Peer Review: 16/05/2015.

Date of Acceptance: 27/05/2015.

Date of Publishing: 02/06/2015. 